Review Article

\title{
Estimating the Possibility of Lead Contamination in Soil Surface due to Lead Deposition in Atmosphere
}

\author{
Nguyen Thi Lan Binh (D), Nguyen Trung Hoang, Nguyen Thi Thanh Truc, Vu Dinh Khang, \\ and Hung Anh Le
}

Institute for Environmental Science, Engineering and Management, Industrial University of Ho Chi Minh City, Vietnam

Correspondence should be addressed to Nguyen Thi Lan Binh; nguyenthilanbinh@iuh.edu.vn

Received 1 March 2021; Revised 12 April 2021; Accepted 23 April 2021; Published 12 May 2021

Academic Editor: Ajit Kumar Sharma

Copyright ( 2021 Nguyen Thi Lan Binh et al. This is an open access article distributed under the Creative Commons Attribution License, which permits unrestricted use, distribution, and reproduction in any medium, provided the original work is properly cited.

\begin{abstract}
An increase in heavy metal soil contamination, especially lead, in the industrial area or near industrial areas has become a serious environmental problem. An industrial zone including paints, electrical plants, metal works, machining, and smelting factories, in the suburban of Ho Chi Minh City, was chosen as the study area. Soil samples were collected from the industrial area and in the residential area next to the industrial area for three experiments, namely, lead content in the surface soils, lead leachate into the water, and movement of lead in soil. Then, the results were compared to the values in the Soil Contamination Countermeasures Law of the Japan Ministry of Environment to assess the possibility of soil contamination which may cause health risks to a human living in that area. The results of the analysis show that the soil has been contaminated by lead. In particular, the lead concentrations of the surface soil samples are $23-35 \mathrm{mg} \mathrm{kg}^{-1}$, while the lead elution of soil samples is quite high, about $0.6 \mathrm{mg} \mathrm{L}$. With these results, the soil can harm people by direct ingestion. More importantly, this work proves that lead species have been going down gradually. To assess the possibility of lead approaching groundwater, more further studies need to be achieved.
\end{abstract}

\section{Introduction}

Lead $(\mathrm{Pb})$ and its compounds may exist in nature or as a product of transportation or metalwork manufacturing, etc. Although lead can be emitted by various sources, industrial sources take a big part in lead contamination [1]. The U.S. EPA in 2014 reported that a high level of airborne lead is found near the industrial operations that materials containing lead, such as metal works, paints... [2]. In recent studies, many scientists also have indicated that high smokestacks of these factories are the factor to spread heavy metal pollution in a wide area [3-5]. Therefore, people who live in the zone that is adjacent to the contamination sources have a high possibility to get health risk from heavy metal contamination.

Lead compounds can be divided into two general categories, namely, inorganic lead and organic lead. The inorganic lead compounds usually consist of lead in a divalent state such as lead carbonate, lead oxide, and lead sulfate, while organic lead compounds, lead tetraethyl and lead tetra- methyl, were found in automotive gasoline [6]. Lead compound particles suspend in the atmosphere for over three weeks and are spread many hundreds of kilometers by the wind and then settle onto the ground through a wet deposition. Particles larger than 10 millimeters, which constitute up to $95 \%$ of the emission, may settle out within short distances [1]. In Vietnam, to control soil pollution, there is a national regulation named National Technical Regulation on the Allowable Limits of Heavy Metals in the Soils [7]. In this, the total lead concentration in a residential area and the industrial area is limited at $120 \mathrm{mg} \mathrm{kg}^{-1}$ and $300 \mathrm{mg} \mathrm{kg}^{-1}$, respectively [7]. However, according to several previous works, a type of soluble lead compounds can cause harm to human health and the environment with small concentrations, while insoluble lead compounds can do with a significant concentration [8].

Humans and animals may inhale or ingest lead that is the main route to exposure to lead. According to Fritz Bischoff et al., there are six lead compounds which are the most toxic 
because of their solubility, namely, ionic lead, colloidal lead hydroxide, metallic lead, glycerophosphate, oleate, and stearate [9], while some insoluble compounds such as lead oxychloride, oxy carbonate, and carbonate are supposed to have less toxicity than soluble compounds, because these insoluble compounds probably are removed from the bloodstream before they have a chance to react with the constituents of the blood. Lead exposure causes some serious harmful effects on various systems in the human body. Various previous studies indicate that lead causes a decrement in neurological function, cognitive function, low IQ, and even cancer. Lead poison also affects the reproductive system, kidney, liver, and gastrointestinal tract [8]. Not only causing an effect on human health, lead deposition also brings some serious problems to the ecosystem. By lead deposition, for a long time, lead species can accumulate within the surface soil and run deeper into groundwater. This may cause a drop in biodiversity, animals, and plants [10,11]. Therefore, controlling soil pollution by total lead concentration will not be relevant to protect people who live near an industrial area. In a study about estimating the atmospheric lead deposition on surface soil pollution by Lan et al., the Soil Contamination Countermeasures Law was applied to assess the lead contamination in an area around a cement factory [12]. For soil and groundwater protection, the Soil Contamination Countermeasures Law was issued by the Japanese government in 2002 [13]. This law declares designated hazardous standards and a designation standard for soil contamination assessment, in which the soil is assessed as contaminated if it exceeds either the soil concentration standard which risks for direct ingestion or the soil leachate standard risk for ingestion of groundwater. In this case, lead and lead compounds are limited to $150 \mathrm{mg} \mathrm{Pb} \mathrm{kg}^{-1}$ soil on soil concentration standard and $0.01 \mathrm{mg} \mathrm{Pb} \mathrm{L}^{-1}$ solution on soil leachate standards [13].

In this study, we used the Japan Soil Contamination Countermeasures Law to assess the lead pollution in the industrial area and the residential area. The goals of this work are to determine the level of lead in soil from the industrial area and its neighborhoods that may cause risk to human health when a lead substance enters the human body by ingestion. Besides, the possibility of lead elution into the ground and the movement of lead through soil layers were also studied.

\section{Experimental Method}

2.1. Study Area. Sample collection was carried out in and around an industrial zone famous for steelwork, electronics, and machinery in Ho Chi Minh City suburban. This industrial zone has 195 hectares for industrial work and 77 hectares for the residents. In recent years, because of employment demand, human density in this area has been increasing quickly and uncontrollably. The increasing population density in a potentially polluted zone raises health safety concerns. Thus, it is necessary to have a study evaluating soil pollution here to serve the health risk assessment in the future.

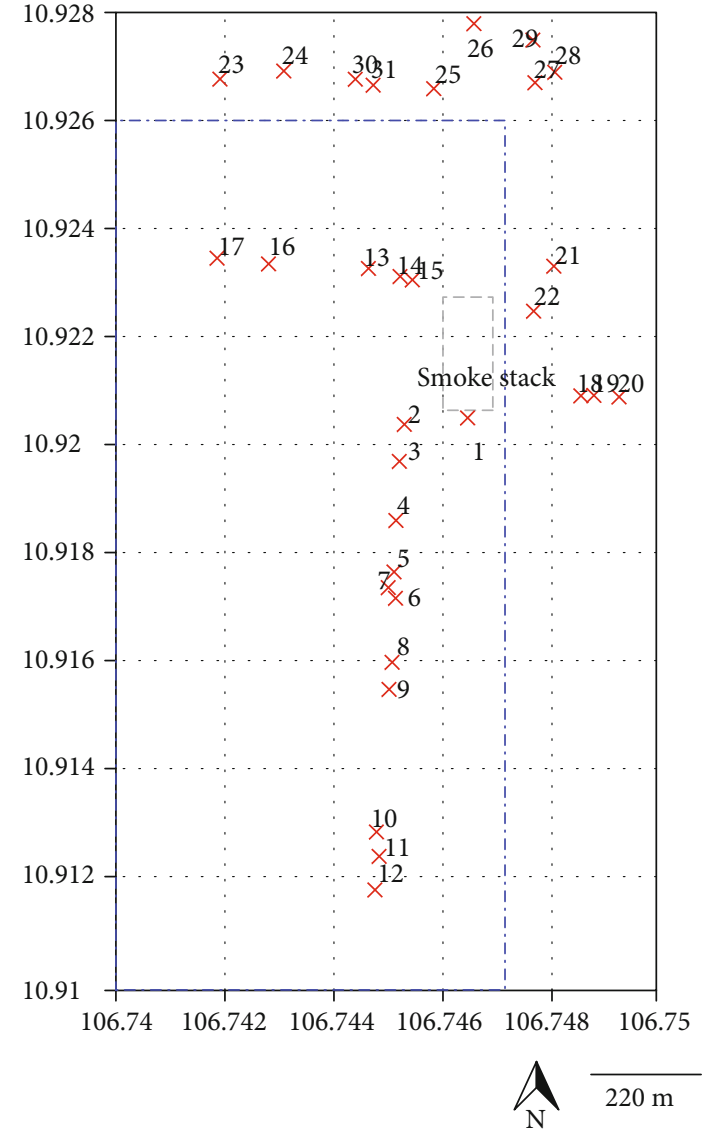

Figure 1: Sampling locations, in which inside the dashed line box are those in the industrial operation, while outside the dashed line box are those in the residential area. The $y$-axis shows the latitude of samples' coordinates while the $x$-axis shows their longitude.

According to the site survey, there are many potential lead contamination sources in the industrial zone, but a smokestack of steelwork factories is supposed to be the main source that can spread polluted aerosols in a wide area. Therefore, to determine the lead contamination due to atmospheric deposition, the steelwork smokestack was chosen as the main source of lead emission.

Wind direction is not certain in this area. Two main directions are north to south and inverse way. For that, the samples were focused on the north-south axis (Figure 1). The soil sampling was taken in late May and during the rainy season of Ho Chi Minh City. Soil samples were always wet. The study area had a warm temperature ranging from $30^{\circ} \mathrm{C}$ to $38^{\circ} \mathrm{C}$ at that moment. The soil in the area was characterized by loam, sandy, and clay.

2.2. Sample Procedure. To determine the lead content and lead elution, a total of 31 surface soil samples including 17 samples in the industrial area and 14 samples in the residential area were collected in a radius of 1 kilometer from the steelwork factory's stack (Figure 1). The sample sites were not distributed evenly in the study area because the land is almost covered by roads and factories in the industrial area. Surface soil samples were collected at the depth of $0-2$ 


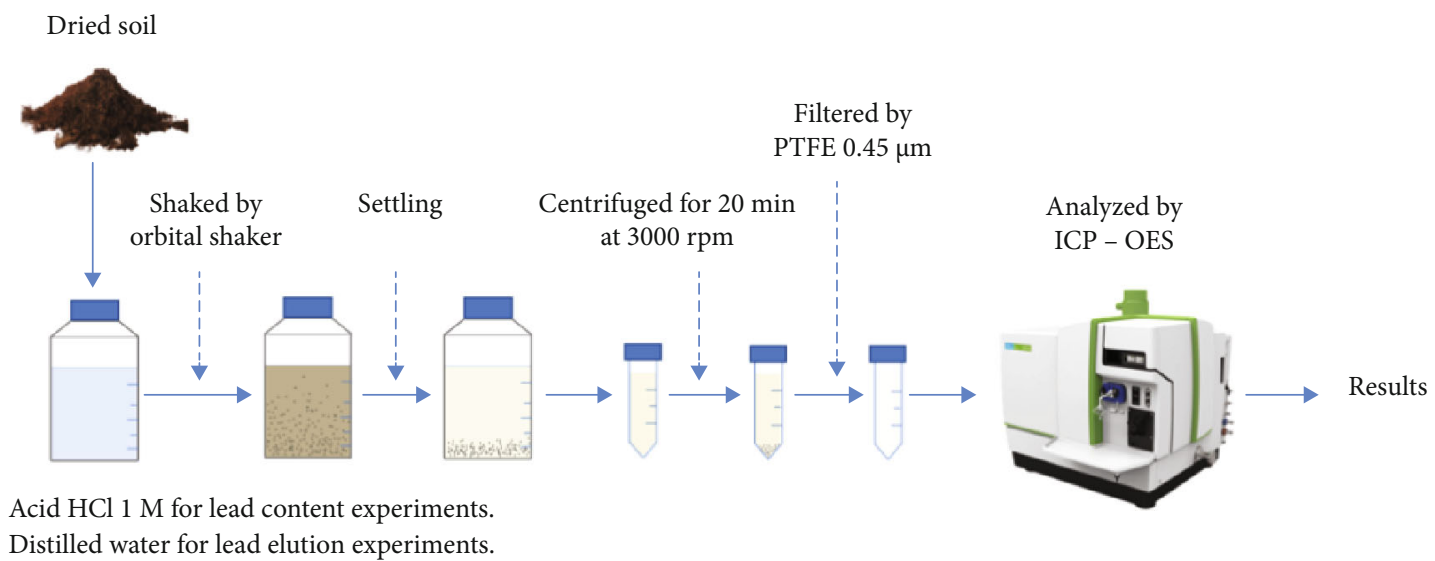

FIGURE 2: Lead content and lead elution analysis method schematic.

centimeters after cleaning off the grass, waste, rocks, and so on. 31 soil samples are divided into 4 groups which represent for their location that correlate with the smokestack on the map, in which samples 1 to 12 are in the south of the smokestack, samples 13 to 17 are in the east, samples 18 to 22 are in the west, and samples 23 to 31 are in the north.

Soil layer samples were also collected from six spots within the study area to estimate a lead moving into the soil. These spots were decided by three spots in the industrial area and three others in the residential area. Four layers of samples were collected at every 2 centimeters from the surface samples. All soil samples were sieved through to 2 millimeters of plastic sieve opening to remove vast wastes, rock, etc. Finally, each analytical sample was stored in a zip lock bag.

\subsection{Elemental Analysis}

2.3.1. Measurement of Lead Content in Soil Samples. In this work, the lead content $\left(\mathrm{mg} \mathrm{kg}^{-1}\right)$ of each soil sample was analyzed to estimate the risk of lead contamination in the industrial zone and the residential zone. Sample preparation followed the Japanese Ministry of the Environment's Notification No. 9 [14]. The general method schematic is shown in Figure 2. For lead concentration in soil experiment, a dried soil sample was mixed with hydrochloric acid $(\mathrm{HCl}) 1 \mathrm{M}$ with the ratio of 3 grams of soil in $100 \mathrm{~mL}$ acid. At first, a sample emulsion was prepared by putting 6 grams of dry soil into a $250 \mathrm{~mL}$ polypropylene bottle then adding gradually $\mathrm{HCl}$ $1 \mathrm{M}$ to $200 \mathrm{~mL}$. $\mathrm{HCl}$ was purposely controlled at $1 \mathrm{M}$ to simulate acid in the human stomach that helps to estimate the risk of lead contamination to human health when people or children accidentally ingest. The mixture of soil and $\mathrm{HCl}$ $1 \mathrm{M}$ had been shaken for 2 hours at 200 rounds per minute. Then, the solution had been settled for $20 \mathrm{~min}$ before centrifuging for 20 minutes at 3000 rounds per minute. The centrifuged solution was filtered with a $0.45 \mu \mathrm{m}$ pore size syringe filter PTFE membrane before being analyzed by inductively coupled plasma optical emission spectrometry (ICP-OES Spectroblue, Spectro Ametek, Germany).

ICP-OES uses unit $\mathrm{mg} \mathrm{L}^{-1}$ to represent the content of solution lead. To make a comparison with the regulations, we have to change the unit $\mathrm{mg} \mathrm{Pb} \mathrm{L}^{-1}$ of the volume of sample solution to unit mg $\mathrm{Pb} \mathrm{kg}^{-1}$ of dried soil which is showed in

$$
C_{1}\left(\frac{\mathrm{mg}}{\mathrm{kg}}\right)=\frac{C_{2}(\mathrm{mg} / \mathrm{L}) \times(V(\mathrm{~mL}) / 1000)}{M_{\text {soil }} / 1000}
$$

in which $C_{1}$ is the lead concentration in soil $\left(\mathrm{mg} \mathrm{kg}^{-1}\right), C_{2}$ is the lead concentration in ICP-OES result $\left(\mathrm{mg} \mathrm{L}^{-1}\right), V$ is the volume of $\mathrm{HCl} 1 \mathrm{M}(\mathrm{mL})$, and $M_{\text {soil }}$ is the weight of soil extracted in $\mathrm{HCl} 1 \mathrm{M}$ (gram). In this study, $M_{\text {soil }}=6$ grams.

2.3.2. Measurement of Lead Elution into Groundwater. Soil leachate into groundwater was carried on to determine the concentration of lead that can dissolve in water. Sample preparation and analysis methods are based on the method shown in the Japanese Ministry of the Environment's Notification No. 9 [14] and the study of Nguyen et al. in 2018 [12]. According to Figure 2, the method of lead elution analysis is quite similar to lead content experiment but we replaced acid with distilled water. Firstly, $10 \mathrm{~g}$ of dried soil was mixed with $100 \mathrm{~mL}$ distilled water with a ratio of 1 gram of soil in $10 \mathrm{~mL}$ water. The emulsion was contained in a polyethylene container. And then, it had been shaken for 6 hours at a speed of 200 rounds per minute. After 40 minutes of the sedimentation, the solution was poured into a Falcon tube and then centrifuged for 20 minutes at 3000 rounds per minute. Finally, the sample solution was filtered with a $0.45 \mu \mathrm{m}$ pore size syringe filter PTFE membrane before being analyzed by ICP-OES. The result of lead elution is shown in the unit of $\mathrm{mg} \mathrm{L}^{-1}$.

\section{Results and Discussion}

3.1. Lead Content in Surface Soil Samples May Cause a Health Risk. We assume that if a child playing in the study area accidentally eats a certain amount of soil, will the child have any adverse health effect? Figure 3 depicts the lead concentration in soil can dissolve in $\mathrm{HCl} 1 \mathrm{M}$ which imitated human's stomach acid. In this work, the lead concentration fluctuates from $23 \mathrm{mg} \mathrm{kg}^{-1}$ to $35 \mathrm{mg} \mathrm{kg}^{-1}$. However, there were 6 samples with nonlead detection occupying $20 \%$ of the total amount of samples. This proportion is very interesting. In this work, 31 


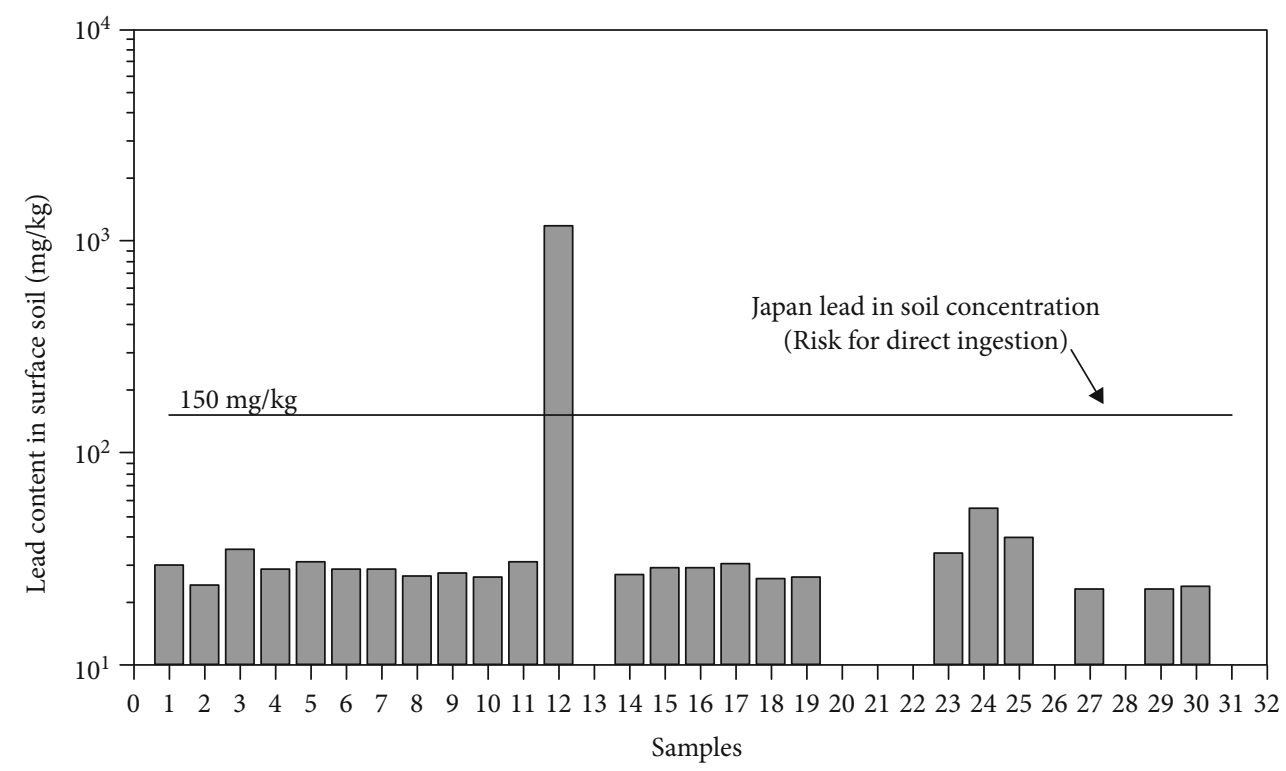

FIGURE 3: Lead content results of surface soil samples compared to Japanese lead in soil concentration standard at $150 \mathrm{mg} \mathrm{kg}^{-1}$.

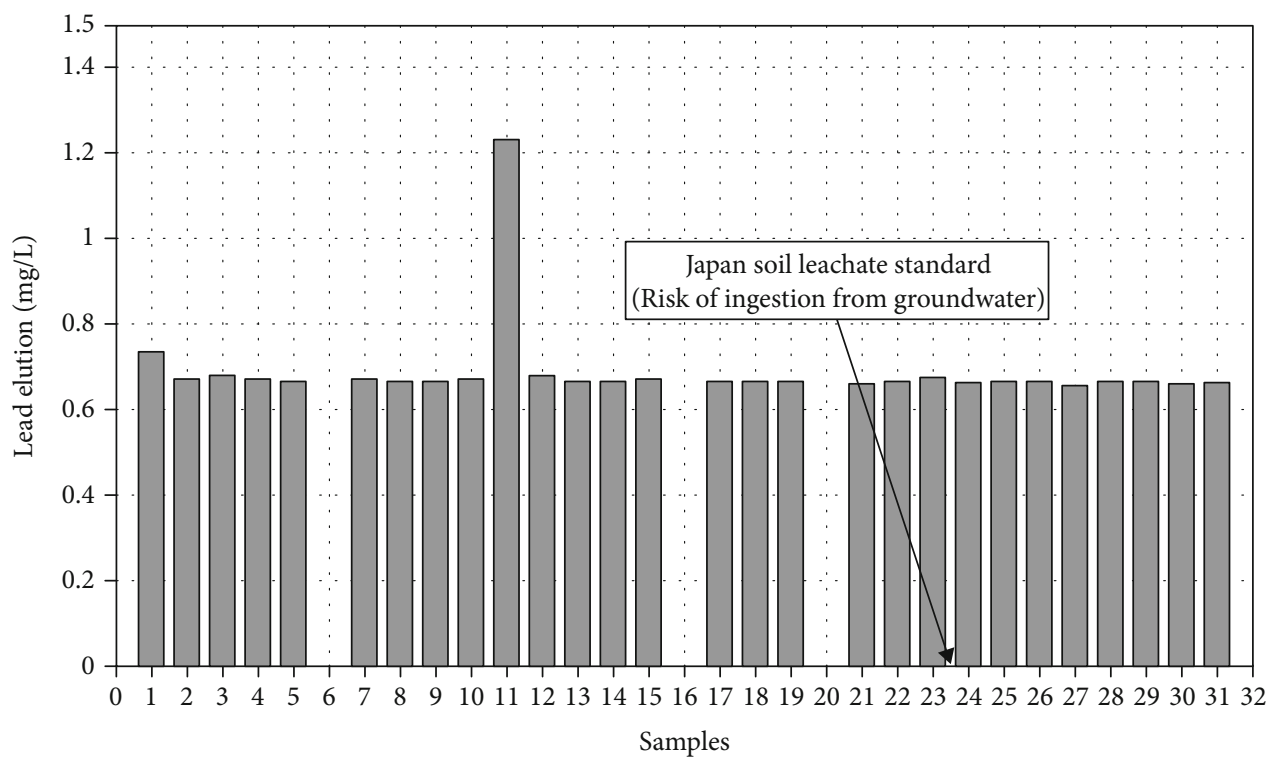

FIGURE 4: Lead elution results of surface soil samples compared to Japanese soil leachate standard at $0.01 \mathrm{mg} \mathrm{L}^{-1}$.

soil samples are separated into four groups which represent for their locations mentioned in Sample Procedure. We notice that nonlead samples C20, C21, and C22 are on the west of the smokestack while nonlead samples C26, C28, C31, and C32 are on the north of the smokestack. We suppose that wind direction has played an important role in air pollution spread. The airborne heavy metals have tended to move to the south because of the wind. Lead concentrations in most of the samples are 4-6 times lower than the risk threshold of the Japanese Soil Contamination Countermeasures Law (150 $\mathrm{mg} \mathrm{kg}^{-1}$ ) [13] and 8-12 times lower than that in the Vietnamese Heavy Metal Limit in Soil Regulation (300 $\mathrm{mg} \mathrm{kg}^{-1}$ ) [7], except for sample C12. However, it should be noted that the Vietnamese regulation on lead concentra- tions above is the concentration in the soil. In the fact that only soluble lead compounds affect human health, sample $\mathrm{C} 12$ has a remarkably high lead concentration, $1187 \mathrm{mg} \mathrm{kg}^{-1}$. This may be due to some exotic agents causing high lead contamination such as batteries and paint waste on the ground.

According to the site survey in this industrial zone, we suppose that there are two major lead emission sources, namely, a steelwork factory and a paint factory. A paint factory undoubtedly is a source of heavy metal contamination in soil [15]. Nevertheless, the paint factory is a point pollution source that cannot spread airborne heavy metal in a large area. Look at Figure 3; samples C27, C29, and C30, which are about 800 meters away from the steelwork factory stack, also have quite the same lead concentration as 


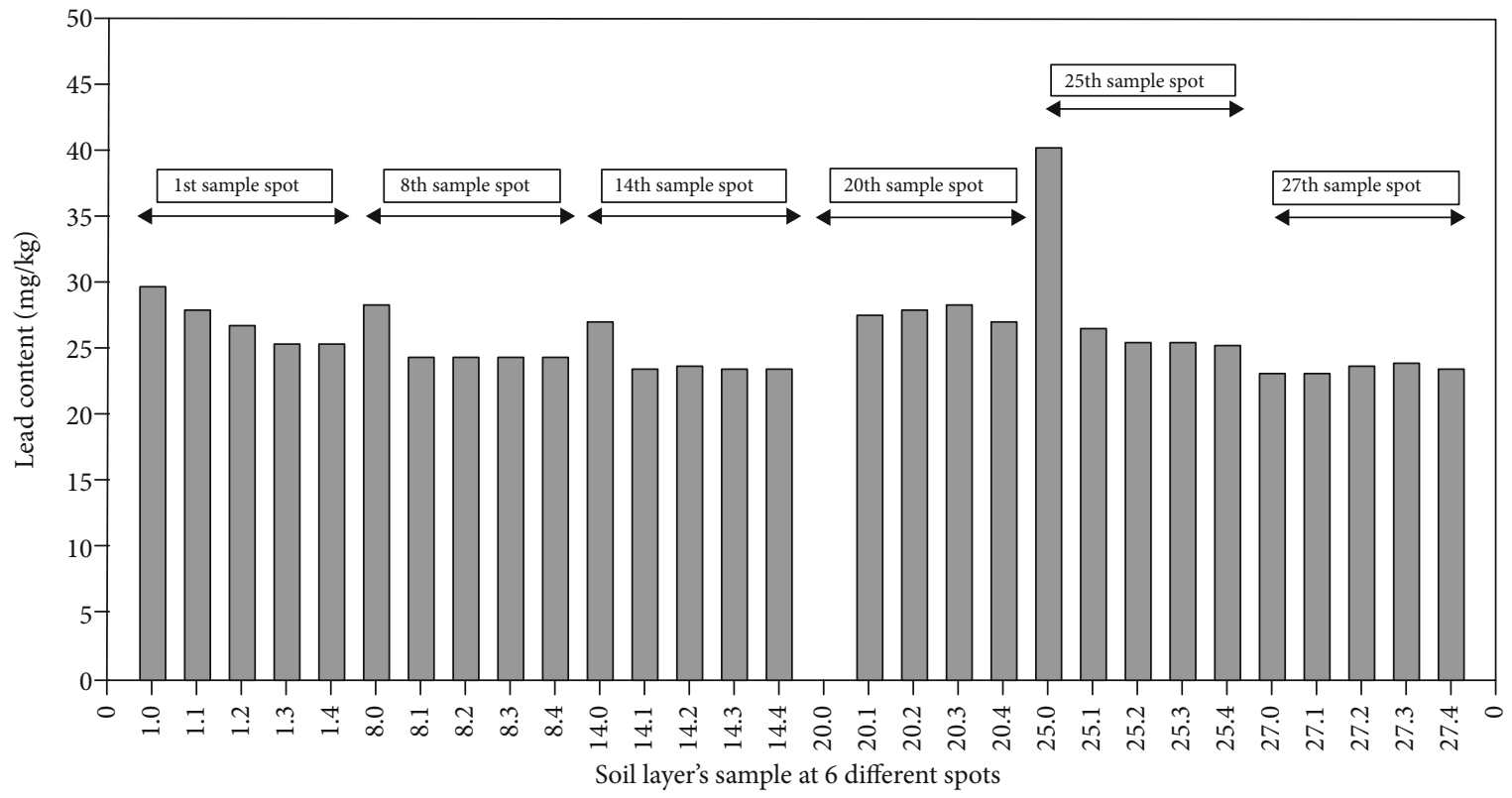

FIGURE 5: Lead content results in soil layer samples. There were 5 layers of soil from $0 \mathrm{~cm}$ to $10 \mathrm{~cm}$ at each sample spot alternatively: $1^{\text {st }}$ sample spot, $8^{\text {th }}$ sample spot, $14^{\text {th }}$ sample spot, $20^{\text {th }}$ sample spot, $25^{\text {th }}$ sample spot, and $27^{\text {th }}$ sample spot.

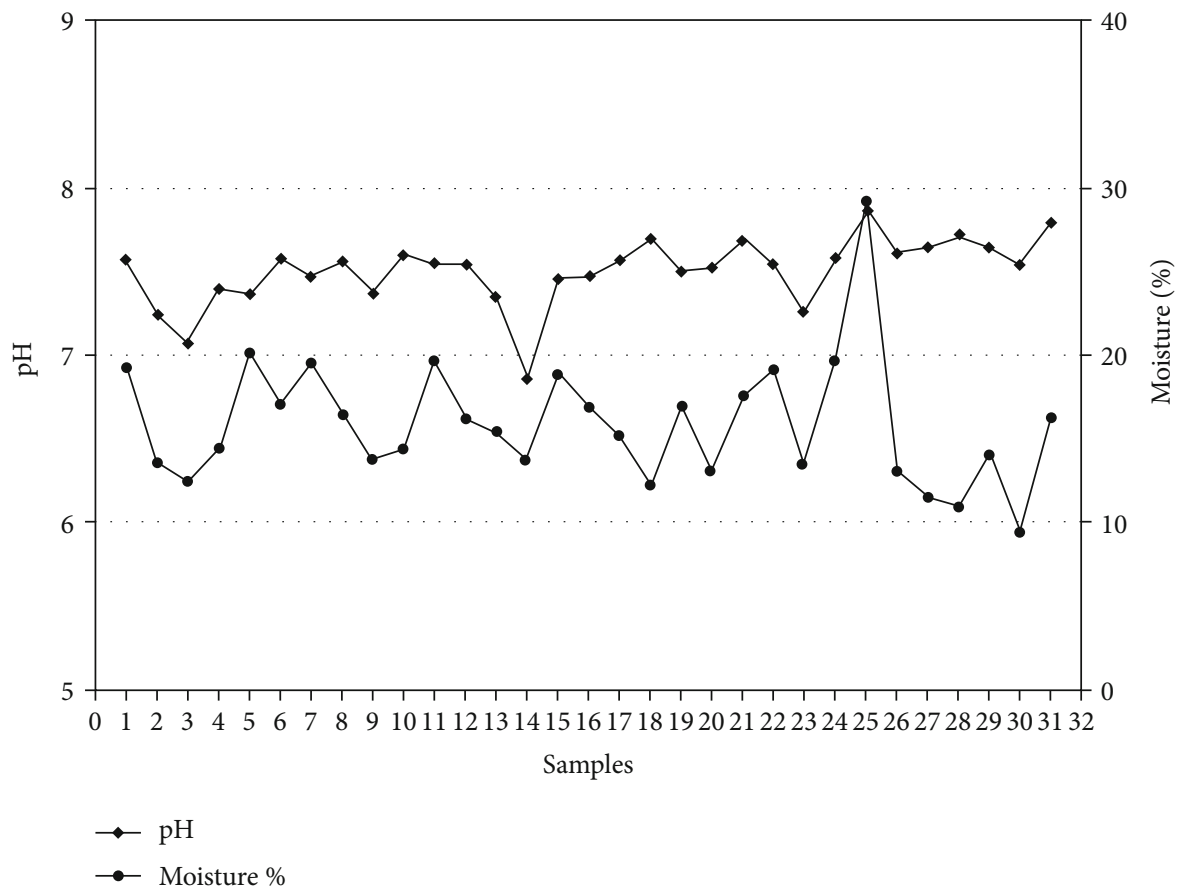

FIgURE 6: $\mathrm{pH}$ and moisture of 31 soil samples.

that of samples near the stack. Because of that, we stated that the 25-meter stack of steelwork factory is the main heavy pollution source in the study area. More interestingly, this steelwork factory is established in 2012, but the lead contamination level in the residential area is as high as in the industrial area. Therefore, the lead content that accumulates gradually in the future will cause serious risks to the residence.
3.2. Lead Elution into Groundwater. Similar to the lead content in surface soil experiments, 31 soil samples from Section 3.1, which are so-called E1 to E31, were extracted by water. Lead concentrations are shown in Figure 4. In general, the lead elution of most soil samples is much higher than the upper limit in the Japanese Soil Contamination Countermeasures Law $\left(0.01 \mathrm{mg} \mathrm{L}^{-1}\right)$ [13]. This is truly dangerous for children playing at a playground who may drink water on the 
ground accidentally. There are 3 water samples that had nondetected results, while 27 water samples have a lead elution 60 times higher than that of threshold in the law. In particular, sample E11 has a lead concentration over 120 times more than the threshold.

In industrial works, there are many kinds of lead compounds that exist. However, this result shows that the lead contamination in the study area is contributed by highly dissolvable lead substance's proportion, for example, lead acetate, lead chloride, and lead nitrate. The dissolvable lead substances are really dangerous to human health. Moreover, with high lead elution, the groundwater is soon contaminated with lead.

3.3. Lead Concentration in Soil Layers. Lead species tend to follow the water flow upon going down. However, the movement of lead through the soil is slow because a strong tendency to be adsorbed onto organic matter and clay particles makes it immobile and biologically inert. In 1996, Maskall et al. examined soil samples in the lead-smelting site, which proved no movement farther than 70 centimeters in 200 years [16]. The mobility of lead in soil depends on various factors, for instance, the type of soil, $\mathrm{pH}$, moisture content of the soil, and water infiltration. In this experiment, there are three types of soils in which loam appears in samples No. 1, No. 8, No. 20, and No. 25; clay appears in sample No. 14; sand appears in sample No. 27. Lead concentrations in each soil layer as data for the movement of lead examiners are reported in Figure 5. Generally, samples No. 1, No. 8, No. 14 , and No. 25 have the same trend, the concentration of lead in the lower layers slice lower than that in the surface layer. Mostly, the lead at 10 centimeters from the surface is around $23 \mathrm{mg} \mathrm{kg}^{-1}$ to $28 \mathrm{mg} \mathrm{kg}^{-1}$. Water passes slowly through the loam soils and more slowly in the case of clay. That is why lead moves gradually from the surface to the lower layers. In contrast, sandy soils do not hold water well and it goes down quickly. In the results of sample No. 27, the lead contents at the surface and lower layers show no difference.

The $\mathrm{pH}$ and moisture of soil also impact the movement of lead. Figure 6 shows the results of $\mathrm{pH}$ and the moisture $\%$ of each surface soil sample. The $\mathrm{pH}$ of the soils in this work fluctuated from 6.9 to 8 . At neutral or higher $\mathrm{pH}$, the soil holds lead species strongly. Usually, atmospheric lead is deposited on the surface of the soil (2-5 centimeters) and retains in it when $\mathrm{pH}$ is higher than 5 [17].

\section{Conclusions}

Lead exists in many forms in the environment. It can come from natural sources such as in ores or from nonnatural sources such as from industrial activities and transportation. Usually, lead and its compounds emitted from industrial works are hazardous. These toxic materials are released into an industrial zone's atmosphere every day. And then, they get into the soil by the wet deposition process. More importantly, the population density near the industrial zone is increasing rapidly in Vietnam that raised up a concern in health safety. After this study, according to the Soil Contamination Countermeasure Law of Japan, the surface soil in the industrial area and near the industrial area has been contaminated by lead, even though the lead concentration is lower than the upper limit. Interestingly, the lead elution is too much higher, about 60 to 120 times more than the safety threshold. The lead elution will affect groundwater sooner or later.

\section{Data Availability}

No data were used to support this study.

\section{Conflicts of Interest}

The authors declare that they have no conflicts of interest.

\section{References}

[1] I. Thornton, R. Rautiu, and S. Brush, "Lead: The Facts," vol. 40, no. 2, 2001

[2] EPA, Report on the environment - lead emission, 2014.

[3] R. A. Wuana and F. E. Okieimen, "Heavy metals in contaminated soils: a review of sources, chemistry, risks and best available strategies for remediation," ISRN Ecology, vol. 2011, Article ID 402647, 20 pages, 2011.

[4] K. Šichorová, P. Tlustoš, J. Száková, K. Kořínek, and J. Balík, "Horizontal and vertical variability of heavy metals in the soil of a polluted area," Plant, Soil and Environment, vol. 50, no. 12, pp. 525-534, 2011.

[5] R. Martin, K. Dowling, D. Pearce, J. Sillitoe, and S. Florentine, "Health effects associated with inhalation of airborne arsenic arising from mining operations," Geosciences, vol. 4, no. 3, pp. 128-175, 2014.

[6] National Toxicology Services Program Department of Health and Human, Report on carcinogens-lead and lead compounds, Natl. Toxicol. Serv. Progr. Dep. Heal. Human, 14th edition, 2004.

[7] “QCVN 03 : 2008 / BTNMT Quy chuẩn kỹ thuật quốc gia trong đất National technical regulation on the allowable limits of heavy metals in the soils," 2008.

[8] H. Abadin, A. Ashizawa, Y.-W. Stevens et al., "Toxicological profile for lead," 2019.

[9] R. D. E, F. R. N. F. Bischoff, and L. C. Maxwell, "Studies on the toxicity of various lead compounds given intravenously," Journal of Pharmacology and Experimental Therapeutics, vol. 34, pp. 85-109, 1928.

[10] "Air pollution from Lead. General information on lead, and the TCEQ planning activities addressing the lead standardTexas Commission on Environment QualityJune 2019, https://www.tceq.texas.gov/airquality/sip/criteria-pollutants/ sip-lead.

[11] A. L. Wani, A. Ara, and J. A. Usmani, "Lead toxicity: a review," Interdisciplinary Toxicology, vol. 8, no. 2, pp. 55-64, 2015.

[12] B. Nguyen Thi Lan, T. Kobayashi, A. Suetsugu, X. Tian, and T. Kameya, "Estimating the possibility of surface soil pollution with atmospheric lead deposits using the ADMER model," Sustainability, vol. 10, no. 3, p. 720, 2018.

[13] S. Aoki, "Soil contamination countermeasures law," Japan Tappi Journal, vol. 57, no. 10, pp. 1475-1493,021, 2003.

[14] "The lead content in the soil was measured by the Japan Ministry of the Environment, Notification N.19," 2004, September 2019, http://www.env.go.jp/hourei/06/000029.html. 
[15] W. Ji, T. Yang, S. Ma, and W. Ni, "Heavy metal pollution of soils in the site of a retired paint and ink factory," Energy Procedia, vol. 16, pp. 21-26, 2012.

[16] J. Maskall, K. Whitehead, C. Gee, and I. Thornton, "Long-term migration of metals at historical smelting sites," Applied Geochemistry, vol. 11, no. 1-2, pp. 43-51, 1996.

[17] S. C. Xintaras, Impact of lead-contaminated soil on public health, U.S. department of health and human services, Public Health Service, Agency for Toxic Substances and Disease Registry, Atlanta, Georgia, 1992, https://wonder.cdc.gov/wonder/ prevguid/p0000015/p0000015.asp. 